\title{
LIVE OR LET DIE: WILL THE COURTS RECOGNIZE IN Terminally Ill Patients a Fundamental Right to CHOOSE NON-FDA APPROVED DRUGS OR DOES THE FDA's Stringent Approval Process Carry SUFFICIENT MERIT?
}

\author{
Clayton R. Portell
}

TABLE OF CONTENTS

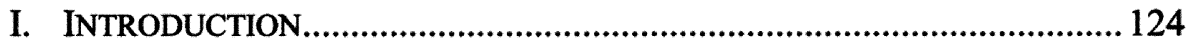

II. THE FDA AND ITS STRINGENT APPROVAL PROCESS ......................... 126

A. Drug Regulation is No New Concept ...................................... 126

B. History of the Food and Drug Administration ........................ 127

C. The FDA's Current Drug Approval Process.......................... 128

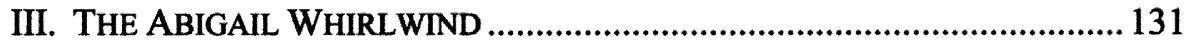

A. A Brief Setting for the Case .................................................... 131

B. A Glimpse of Hope ................................................................ 131

C. Hope Denied? ....................................................................... 134

D. Hope for a Better Tomorrow? ............................................... 136

IV. SHOULD THE TERMINALly ILl BE Allowed TO CHOOSE? ............... 137

A. Considerations in Favor of Deregulation ............................... 137

B. Considerations Against Deregulation ..................................... 140

C. Legal Concerns Regarding Deregulation Versus the

Right of Terminally Ill Patients to Choose Non-FDA

Approved Drugs ....................................................................... 143

V. THE FUTURE OF THE FDA's APPROVAL PROCESS REGARDING

TERMINALLY ILl PATIENTS' ACCESS TO UNAPPROVED DRUGS .... 145

A. A Preemptive Strike? ............................................................. 145

B. Legislative Action................................................................. 145

C. Drug Regulation Around the World...................................... 149

1. Great Britain .................................................................. 149

2. Germany ................................................................. 150

3. World Health Organization............................................. 151

D. Privatization as an Alternative ............................................ 151

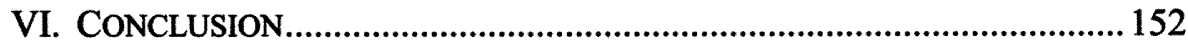

* J.D. Candidate, 2008, Indiana University School of Law - Indianapolis; B.A., 2005, Southeast Missouri State University, Cape Girardeau, Missouri. I would like to thank the editors and staff of the Indiana Health Law Review for all of their help along the way. Special appreciation also goes to my wife Starla and my parents for their love, support, and encouragement. 


\section{INTRODUCTION}

Taking into account the number of patients who have died without access to potentially life-saving drugs, the current state of drug approval in the United States is in need of change. To what extent the current regulatory system should be changed has become a highly controversial and debated topic throughout the nation. With strong arguments on both sides of the issue, one thing remains evident: Too many patients have suffered through their last days with little or no hope. Appropriate adjustments to the Food and Drug Administration's ("FDA") regulatory structure could deliver that much deserved and long awaited hope.

It is estimated that, in 2006 , nearly 1.4 million "terminally ill"1 patients in the United States lost their battle, many having been denied access to potentially lifesaving treatments. ${ }^{2}$ While there are hundreds of drugs manufactured every year, many of them will not make it to the very patients whom they were designed to protect until it is too late. This is because there is a lengthy approval process that has been established by the FDA. In fact, over the last five years, the FDA's average approval rate for new drugs is just twenty-three a year. ${ }^{3}$ The United States is recognized as having one of the most regulated and demanding drug approval systems in the world. ${ }^{4}$ The result of this elaborate system is that many patients, despite the fact that they face imminent death, are denied the chance to prolong or even save their lives.

Over the past two decades, there has been much criticism aimed at the FDA's current drug approval system. This criticism has been the topic of numerous articles, notes, and even court decisions. Until recently, however, the government has stood behind the FDA's conservative approach and its reasoning for initially establishing the debated process. While the integrity of the system, one which often comes between near-death patients and the hope of a potential cure, has frequently been called into question, the FDA has repeatedly been held to be the paramount authority on the issue. The tenure of the FDA's supreme authority may, however, soon come to an end.

On May 2, 2006, the United States Court of Appeals for the District of Columbia Circuit rendered a decision that sent shockwaves through the medical community. ${ }^{5}$ In Abigail Alliance for Better Access to Developmental Drugs $v$.

1. "Terminally Ill" refers to a person, suffering from a disease, who is not expected to live more than 12 months. See Dictionary.com, http://dictionary.reference.com/browse/ terminally\%20ill (last visited Feb. 27, 2008).

2. See generally Cancer Facts and Figures 2006, Issue REP. (Am. Cancer Soc'y, Okla. City, Okla.), 2006, at 1-56, available at http://www.cancer.org/downloads/STT/ CAFF2006PWSecured.pdf.

3. Jerome Groopman, The Right To a Trial: Should Dying Patients Have Access to Experimental Drugs?, THE NEW YORKER, Dec. 18, 2006, at 40.

4. John Patrick Dillman, Note, Prescription Drug Approval and Terminal Diseases: Desperate Times Require Desperate Measures, 44 VAND. L. REV. 925, 927 (1991).

5. Abigail Alliance v. Eschenbach, 445 F.3d 470 (D.C. Cir. 2006), vacated, 495 F.3d 
Eschenbach, a three judge panel of the court ruled, in a two to one decision, that terminally ill patients have a fundamental right to drugs that have not been fully approved by the FDA. ${ }^{6}$ For the next couple of months the extent of the decision became the topic of debate in the media and medical community as numerous concerns arose. Flurries of questions were posed, such as: How much regulation was necessary before access would be permitted? Who exactly would be permitted access to unapproved drugs? Would the decision of the U.S. Court of Appeals for the District of Columbia survive before the Supreme Court if the FDA were to appeal? Recognizing the serious implications of its decision, the U.S. Court of Appeals for the District of Columbia, on November 21,2006 , decided to vacate its previous decision and to conduct a rehearing. On August 7, 2007, the Court reversed its previous decision and held that patients do not have a fundamental right to experimental drugs. ${ }^{7}$ While the decision struck a blow to cancer patients and advocacy groups around the nation, it is expected that the case will reach the United State Supreme Court within the next couple of years.

While it is uncertain how the Supreme Court will decide the issue, it is evident that there exist both ethical dilemmas and legal concerns regarding the rights of dying patients. This Note will concentrate on terminally ill cancer patients and their access to experimental drugs that have not been approved by the FDA. ${ }^{8}$ Because of the unique nature of terminal diseases, the FDA's conservative approval process raises even greater concerns. The FDA requires that new drugs pass three phases of testing before being introduced on the market. ${ }^{9}$ Such extensive testing takes, on average, nearly seven years to complete. ${ }^{10}$ However, terminally ill patients, by definition, usually have less than one year to live. ${ }^{11}$ It is obvious that, under current regulations, newly manufactured drugs and recently discovered treatments will often not be available to such terminally ill patients until it is too late.

The FDA is not, however, apathetic to the lives and needs of terminally ill patients. Rather, it was established to serve as a gatekeeper and to protect the health of the nation, including those very patients it is allegedly harming. ${ }^{12}$ The FDA requires such extensive testing for new drugs so that it can screen for potential risks, including side-effects and poisons. ${ }^{13}$ If patients were granted free

695 (2007).

6. Id. at 486 .

7. See Abigail Alliance v. Eschenbach, 495 F.3d 695 (D.C. Cir. 2007).

8. It should, however, be recognized that there are other groups of terminally ill patients, such as those with AIDS and cardiovascular diseases. See Pressure for New US FDA Experimental Drug Regulations Could Create Problems, Pharma MARKETLETTER, Dec. 25, $2006 \S \S$ 1355-8501.

9. See FDA Investigational New Drug Application Rule, 21 C.F.R. § 312.21 (2007); see also infra, Part II.B.

10. Abigail Alliance v. Eschenbach, 445 F.3d 470, 474 (D.C. Cir. 2006).

11. Dictionary.com, supra note 1.

12. Lisa Casanova, The Terminally Ill and Their Right to Drugs, Mises INSTITUTE, July 24, 2006, http://www.mises.org./story/2245 (last visited Feb. 27, 2008).

13. Id. 
access to every new treatment and drug before testing was complete, there is a significant potential that the illness could be worsened or that the drugs could have a lethal effect. For these reasons, the FDA has taken the conservative approach and required intense testing before releasing new drugs. Nevertheless, the FDA has recently taken steps to speed the process and allow for alternative testing methods. ${ }^{14}$

Part II of this Note surveys the history of the FDA and its prescription drug approval process. Part III discusses Abigail Alliance and the potential recognition of a fundamental right in terminally ill patients. Part IV analyzes the ethical dilemma and legal implications involved in the issue. Finally, Part $\mathrm{V}$ of this Note addresses future concerns regarding terminally ill patients' access to new drugs, and proposes modest changes to the current drug approval process. This Note will conclude with a short summary and one law student's take on the drug industry and the idea of deregulating the Food and Drug Administration's current approval process.

\section{THE FDA AND ITS STRINGENT APPROVAL PROCESS}

\section{A. Drug Regulation is No New Concept}

Since nearly the dawn of mankind, there have been regulators of drug and treatment usage. In ancient Egypt, physicians were required to practice in accord with written laws. ${ }^{15}$ Also, during medieval times in Muslim countries, a group known as the muhtasib made inspections and supervised the production of medicine. ${ }^{16}$ In Europe, between the eleventh and twelfth centuries, laws were passed forbidding doctors from keeping and using certain medicines and utilizing the services of certain apothecaries. ${ }^{17}$ Then, the United Kingdom, in 1540, passed the Apothecary Wares, Drugs, and Stuffs Act; thereby, empowering physicians to inspect the premises of apothecaries for certain ineffective drugs. ${ }^{18}$ Interestingly enough, however, the United States was without official drug regulation for over a century after its birth. In fact, the first passage of laws relating to the regulation of pharmaceutical drugs and treatments did not occur until the beginning of the twentieth century.

14. See infra Part V.A.

15. Eshetu Wondemagegnehu, Effective Drug Regulation: What Can Countries Do?, THEME PAPER (World Health Org.,Geniva, Switz.), Mar. 1999, at 5[hereinafter WHO], available at http:// www.who.int/medicinedocs/collect/edmweb/pdf/s2216e/s2216e.pdf.

16. Id.

17. Id.

18. Id. 


\section{B. History of the Food and Drug Administration}

In 1906, Congress enacted the Pure Food and Drugs Act ("1906 Act"). Prior to that time, there was very little national regulation of medicinal drugs in the United States. ${ }^{19}$ The 1906 Act banned the manufacture and distribution of tainted food and drugs and prohibited misleading labeling of the same." "The 1906 Act did not, however, limit individual access to new drugs or regulate therapeutic claims by drug manufacturers." ${ }^{21}$ Thus, a patient could still, as had been the case since the foundation of the United States government, obtain access to any new medicinal drug, so long as doing so was not a narcotics violation. $^{22}$ Though not particularly effective, the 1906 Act remained the standard for three decades.

In 1937, public outcry erupted after more than a hundred people died from ingesting Elixir Sulfanilamide, a drug which had not been tested for safety. ${ }^{23}$ In 1938, the government responded by passing the Food Drug \& Cosmetic Act ("FDCA"). ${ }^{24}$ This Act required, "[f] or the first time . . that drug manufacturers test, and the FDA review, all new drugs for safety." 25 A manufacturer was now required to file a New Drug Application ("NDA") with the FDA, setting forth a drug's safety information, before introducing it to the market. ${ }^{26}$ The Act, however, still did not require affirmative approval from the FDA; thus, a drug could be distributed unless the FDA barred its distribution. ${ }^{27}$ Furthermore, existing drugs were immune from the new rules because the FDCA contained a grandfather clause exempting existing drugs that were subject to the 1906 Act. $^{28}$ Therefore, the pharmaceutical market was still contaminated with drugs that had not been tested for safety.

The most significant change to the FDCA occurred in 1962 when Congress passed the Kefauver-Harris Amendments. ${ }^{29}$ The Amendments arose in response to the discovery that thalidomide, a drug used to relieve morning sickness in pregnant women, caused substantial birth defects. ${ }^{30}$ The 1962 Amendments introduced substantial changes to the way the FDA operated its approval

19. Abigail Alliance v. Eschenbach, 445 F.3d 470, 474 (D.C. Cir. 2006).

20. Charles J. Walsh \& Alissa Pyrich, Rationalizing the Regulation of Prescription Drugs and Medical Devices: Perspectives on Private Certification and Tort Reform, 48 RUTGERS L. REV. 883, 890 (1996).

21. Abigail Alliance, 445 F.3d at 481.

22. Id. at 482 .

23. Walsh \& Pyrich, supra note 20 , at 893 .

24. See 21 U.S.C $\S \S 301-399$ (a) (2007).

25. Abigail Alliance, $\mathbf{4 4 5}$ F.3d at 482 .

26. Id.

27. Id.

28. Walsh \& Pyrich, supra note 20 , at 894 .

29. Id. at 896.

30. Id. See also Dillman, supra note 4, at $925 \mathrm{n} .2$ (explaining that "[i]ronically, because thalidomide caused dramatic side effects in a relatively small class of patients, the true defect may have resulted from a labeling, and not a testing, failure."). 
process. First, they required the FDA to ensure, not only that new drugs were safe, but also that they were effective for their intended purposes. ${ }^{31}$ Furthermore, "the Amendments authorized the FDA to approve human clinical trials, regulate drug advertising, inspect drug-manufacturing facilities, and promulgate good manufacturing practices." ${ }^{32}$ Today's drug approval process is based on the standards set forth in the FDCA and the 1962 Amendments.

General Counsel for the FDA has identified five goals that it strives to meet in each decision and process. ${ }^{33}$ Those goals are: (1) to protect the public from harm through product regulatory mechanisms; ${ }^{34}(2)$ to maximize individual autonomy; ${ }^{35}(3)$ to guarantee public participation in the decision-making process $;{ }^{36}(4)$ to ensure that procedures are consistent and dependable $;{ }^{37}$ and (5) to swiftly render decision upon pending issues. ${ }^{38}$ Whether or not the FDA's current approval process serves each of these goals has sparked debate and created doubt about the agency's methods.

\section{The FDA's Current Drug Approval Process}

The FDCA defines drugs as "articles (other than food) intended to affect the structure or any function of the body of man" and "intended for use in the diagnosis, cure, mitigation, treatment, or prevention of disease in man or other animals." 39 In order to keep adulterated drugs from the public's reach, the FDA requires substantial evidence of safety and efficacy for any "new drug"40 before it can be introduced into interstate commerce." "The term 'substantial evidence' does not mean what it means elsewhere in administrative law, namely, 'such relevant evidence as a reasonable mind might accept as adequate to support a conclusion." 42 Instead, its meaning is derived from purely scientific functions. ${ }^{43}$ In order to implement such precision, the FDA has created a stringent approval process, leaving no room for questionable drugs.

31. Walsh \& Pyrich, supra note 20 , at 897.

32. Abigail Alliance v. Eschenbach, 445 F.3d 470, 482 (D.C. Cir. 2006).

33. Peter Barton Hutt, Food and Drug Regulation in Transition, 35 Food DRUG CosM. L.J. 283, 287-90 (1980).

34. Id. at 288 .

35. Id. at 289 .

36. Id.

37. Id.

38. Id. at 290 .

39. 21 U.S.C. $\S 321(\mathrm{~g})(1)(2007)$.

40. A "new drug" is defined as a drug not "generally recognized, among experts ... as safe and effective for use under the conditions prescribed, recommended, or suggested in the labeling.” 21 U.S.C. $\S 321(\mathrm{p})(1)(2000)$; see also United States v. 50 Boxes More or Less, 909 F.2d 24, 25 (1st Cir. 1990).

41. 21 U.S.C. $\$ 355(a)(2007)$.

42. 50 Boxes More or Less, 909 F.2d at 26 (citing Universal Camera Corp. v. NLRB, 340 U.S. 474 (1951) (quoting Consolidated Edison Co. v. NLRB, 305 U.S. 197, 229 (1938))).

43. "Substantial evidence" means "evidence consisting of adequate and well-controlled investigations, including clinical investigations, by experts.” 21 U.S.C. § 355(d) (2007). 
Before the FDA will accept a NDA, the drug must pass three phases of human clinical testing. ${ }^{44}$ The drug must, however, first complete pre-clinical animal testing before it will even be considered for the first approval phase. ${ }^{45}$ Once the drug has completed appropriate pre-clinical testing, its "manufacturer must apply to the FDA for an Investigational New Drug ("IND") exemption."46 If the IND exemption is granted, the drug may commence the FDA approval process. During the process, the FDA reserves the right to halt testing at any phase if it is not satisfied with the drug's safety and effectiveness. ${ }^{47}$

In Phase I, an IND is introduced "into a small group of healthy human volunteers for a short period of time., ${ }^{, 48}$ Phase I consists of approximately one year of testing, on twenty to eighty human subjects. ${ }^{49}$ Scientists review for any side effects associated with increased dosages and for the preliminary effectiveness of the drug. ${ }^{50}$ FDA counsel has acknowledged "that drugs that survive this phase have been deemed 'sufficiently safe for substantial human testing, but [are] not yet proven to be safe and effective to the satisfaction of the FDA [to be commercially marketed]." "51 However, "[n] early ninety per cent of drugs that enter Phase I trials are eventually abandoned because they are shown to be unsafe or ineffective." 52

Phase II begins a more complete review of efficacy. It involves "controlled clinical studies conducted to evaluate the effectiveness of the drug for a particular indication or indications in patients with the disease or condition under study . . .."53 While the population of Phase II testing is larger than the population of Phase I testing, "drug sponsors still do not include a large number of patients in these trials." ${ }^{\text {" }}$ "The average time for Phase II testing is eighteen months. ${ }^{55}$

Finally, Phase III trials are "intended to gather the additional information about effectiveness and safety that is needed to evaluate the overall benefit-risk

44. 21 C.F.R. $\S 312.21(2007)$.

45. Walsh \& Pyrich, supra note 20, at 904.

46. Id. at 905 .

47. Id. at 906 .

48. Dillman, supra note 4 , at 928 .

49. Walsh \& Pyrich, supra note 20, at 906.

50. FDA Investigational New Drug Application Rule, 21 C.F.R. $\S 312.21$ (a)(1) (2007)

Phase $I$ includes the initial introduction of an investigational new drug into humans. Phase I studies are typically closely monitored and may be conducted in patients or normal volunteer subjects. These studies are designed to determine the metabolism and pharmacologic actions of the drug in humans, the side effects associated with increasing doses, and, if possible, to gain early evidence of effectiveness.

Id.

51. Abigail Alliance for Better Access to Developmental Drugs v. Eschenbach, 445 F.3d

470, 473 (D.C. Cir. 2006) (quoting Oral Argument Tape of Oct. 21, 2005 at 15:57-15:59).

52. Groopman, supra note 3 .

53. FDA Investigational New Drug Application Rule, 21 C.F.R. § 312.21(b) (2007).

54. Dillman, supra note 4 , at 929.

55. Walsh \& Pyrich, supra note 20 , at 907. 
relationship of the drug and to provide an adequate basis for physician labeling." ${ }^{, 56}$ Phase III trials can include several thousand human subjects and last, on average, about three years. ${ }^{57}$

It can take an IND up to twelve years to complete all of the required testing necessary to assure safety and effectiveness. ${ }^{58}$ Approval is not, however, freely given once the phases are complete. After an IND has satisfied the FDA with completion of the three phase approval process, the manufacturer must then apply for a NDA, which is an "exhaustive application, containing nearly every piece of information collected about the drug in the course of laboratory and animal testing as well as in clinical trials." ${ }^{, 59}$ After a comprehensive review of the application, usually lasting three years, the FDA will then decide whether to give approval, or to send the drug back for modifications or further testing. ${ }^{60}$ Overall, approximately seventy percent of new experimental drugs proceed from Phase I to Phase II, and only about thirty-three percent reach Phase III. ${ }^{61}$ Of those drugs that reach Phase III testing, only twenty-five to thirty percent will successfully complete the phase, and about twenty percent will be approved for the market. ${ }^{62}$

The FDA's approval system is exhaustive, extensive, exacting, and expensive. While it can frustrate manufacturers and delay the production of promising drugs, it also protects the public from hazardous products and deters frivolous attempts to enter the drug market. If not for the FDA's creation of its stringent three-phase process, many more dangerous drugs like Elixir Sulfanilamide and thalidomide, might have entered the U.S. market. The FDA is not, however, without its critics. There are a growing number of advocates and lobbyists who are fighting, without regard to cost, to deregulate the drug approval system and allow for easier introduction of and access too new drugs. While the FDA has historically been backed by the government; thereby, maintaining the upper hand in the battle, it appears that the tide of battle may be on the verge of turning.

56. FDA Investigational New Drug Application Rule, 21 C.F.R. § 312.21(c) (2007).

57. Walsh \& Pyrich, supra note 20, at 907.

58. Id. at 933 .

59. Id. at 907-908 (citing FDA Investigational New Drug Application Rule, 21 C.F.R. $§$ $312.21(2007))$.

60. Id. at $\S 909-11$.

61. Marsha N. Cohen, Getting New Drugs to People with AIDS: A Public Policy Response to Lansdale, 18 HASTINGS CONST. L.Q. 471, 474 n.13 (1991).

62. Id. 


\section{THE ABIGAIL WHIRLWIND}

\section{A. A Brief Setting for the Case}

On January 16, 2003, the Abigail Alliance, an advocate group for the terminally ill, submitted a proposal to the FDA asking that post-Phase I INDs be made available to terminally ill patients who were not admitted to the FDA's clinical trials. ${ }^{63}$ After the FDA denied the Alliance's proposal and ignored its Citizen Petition, the Alliance filed suit against the FDA Commissioner, Andrew C. Von Eschenbach, M.D., and the Secretary of the Department of Health and Human Services, Michael O. Leavitt. ${ }^{64}$ The Alliance's suit sought to "enjoin the FDA from enforcing the policy barring the sale of post-Phase I investigational new drugs to terminally ill patients not in Phase II clinical trials."65

Upon review, the District Court dismissed the Alliance's complaint pursuant to a Federal Rule of Civil Procedure $12(\mathrm{~b})(6)^{66}$ motion to dismiss for failure to state a claim upon which relief can be granted. ${ }^{67}$ The Court concluded that the challenged FDA policy was rationally related to a legitimate government purpose. ${ }^{68}$ Thereafter, the Alliance appealed to the United States Court of Appeals for the District of Columbia, which rendered a decision that not only gave hope to thousands of terminally ill patients, but also caused a significant stir in the media and medical community.

\section{B. A Glimpse of Hope}

After reviewing party briefs and hearing oral arguments, an en banc panel (the "Panel") of the Circuit Court rendered its decision on May 2, 2006. ${ }^{69}$ In a 2-1 decision, a new fundamental right was recognized, granting terminally ill patients access to post Phase I drugs and treatment when no other alternatives exist. $^{70}$ Knowing that there was little precedent on the subject, and that such a decision would be the subject of much criticism, the court turned to the Constitution for authority to recognize this right.

The Due Process Clause of the Fifth Amendment of the United States Constitution states, in pertinent part, that "[n]o person shall be ... deprived of life, liberty, or property, without due process of law."71 A Constitutional right, falling under such a clause, is generally recognized as a fundamental right. The

63. Abigail Alliance v. Eschenbach, 445 F.3d 470, 473 (D.C. Cir. 2006).

64. Id. at 473-74.

65. Id. at 474 .

66. FED. R. CIV. P. 12(b)(6).

67. Abigail Alliance, 445 F.3d at 474.

68. Id. at 475 .

69. Id. at 470 .

70. Id. at 486 .

71. U.S. CoNST. amend. V (emphasis added). 
Panel turned to the Supreme Court for guidance in examining an asserted fundamental right. The issue was examined in Washington $v$. Glucksberg. ${ }^{72}$ It noted that a Court must consider "whether the fundamental right asserted is objectively 'deeply rooted in this Nation's history and tradition,' and 'implicit in the concept of ordered liberty, such that neither liberty nor justice would exist if it were sacrificed." "73 When such a right is found, if the government cannot prove a compelling interest in retaining control over the specific area, applicable citizens will assume the right. ${ }^{74}$

There are two components of the Glucksberg analysis. The first component requires courts to compose a "careful description" of the asserted fundamental liberty interest at stake. ${ }^{75}$ The description must not be too broad, or contain a greater population or a greater liberty interest than what is actually recognized by the right. Rather, the description must be narrowly tailored to the "most specific level at which a relevant tradition protecting, or denying protection to, the asserted right can be identified."

Applying these guidelines, the Panel found that the Alliance's complaint contained such a careful description. ${ }^{77}$ The Alliance's claim did not state an overly broad right of access to all new or investigational new drugs; nor, did it claim a right to receive treatment at the government's expense. ${ }^{78}$ Further, the claim did not violate or challenge the Controlled Substances Act. ${ }^{79}$ Instead, "the Alliance contends that the fundamental due process rights to privacy, liberty, and life include the right of terminally ill patients, acting on a doctor's advice, to obtain potentially life-saving medication when no alternative treatment approved by the government is available." ${ }^{, 80}$ This description was found by the Panel to be careful enough to meet the "careful description" requirement of the Glucksberg test. It held that the claimed right was narrowly tailored to terminally ill patients and applied only in situations when their medication is potentially life-saving and no alternatives exist. ${ }^{81}$ Further, the right only applied to

72. Washington v. Glucksberg, 521 U.S. 702, 702 (1997) (holding that there existed no fundamental right to commit suicide or to assistance in doing so, and that State's ban on assisted-suicide was rationally related to legitimate government interests).

73. Abigail Alliance, 445 F.3d at 476-77 (quoting Glucksberg, 521 U.S. at 721 (internal quotation marks omitted)).

74. Id. at 477 .

75. Glucksberg, 521 U.S. at 721.

76. Abigail Alliance, 445 F.3d at 477 (quoting Michael H. v. Gerald D., 491 U.S. 110, $127(1989))$.

77. Id. at 478 .

78. Id.

79. 21 U.S.C. $\S \S 801-961$ (2000). The statute regulates substances that are considered harmful to the public's health, safety, and welfare. If the Alliance's claim called for the use of narcotics, such as marijuana, it would be repugnant to existing federal law and, therefore, invalid.

80. Abigail Alliance, 445 F.3d at 478.

81. Id. at 486 . 
drugs which had completed Phase I of the FDA's approval process; thereby, reducing the chance of unknown risks. ${ }^{82}$

The second component of the Glucksberg test requires courts to inquire whether there is a long-standing tradition in the United States that protects the asserted right. $^{83}$ In response, the FDA argued that it has had statutory authority to regulate drugs for nearly a hundred years, and that such authority was ingrained in the role of the government. ${ }^{84}$ The Panel, however, was not persuaded that the FDA's authority was so deeply rooted in our Nation's history as to constitute a long-standing tradition. Instead, the Panel found a different tradition, one which supported the Alliance's claim.

Specifically, the Panel asserted that "[a] right of control over one's body has deep roots in the common law" including "a person's legal and uninterrupted enjoyment of his life, his limbs, his body, [and] his health,' as well as 'the preservation of a man's health from such practices as may prejudice or annoy it." 85 Also recognized in American history is the defense of necessity, or the right of self-preservation, which allow for extreme measures, not ordinarily justified, when a person is faced with death. ${ }^{86}$ The defense of necessity allows for the destruction of property, including that of another's, if it is necessary to preserve human life. ${ }^{87}$ The FDA's regulation of potentially life-saving treatment impinges on this right of self-preservation. ${ }^{88}$ Furthermore, while the common law does not impose a duty to rescue or to preserve the life of another, it does create liability for interfering with such rights. ${ }^{89}$

Finally, the Panel looked to similar due process caselaw governing a person's fundamental right to self-autonomy. In Cruzan v. Director, Missouri Dept. of Health, the Supreme Court explained that a person has a fundamental right to refuse life-sustaining treatment. ${ }^{90}$ There, the Supreme Court stated that "[n]o right is held more sacred, or is more carefully guarded, by the common law, than the right of every individual to the possession and control of his own person, free from all restraint or interference of others, unless by clear and unquestionable authority of law." In Abigail Alliance, the Panel found the Supreme Court's reasoning to be similarly applicable to the issue of drug access,

82. Id. at 478 .

83. Id. at 479 .

84. Id. at 480 .

85. Id. (quoting WILliam BLACKSTONE, 1 COMMENTARIES 125, 130 (1765)).

86. Id.

87. See George C. Christie, The Defense of Necessity Considered From the Legal and Moral Points of View, 48 DUKE L.J. 975, 988 (1999). Professor Christie discusses a line of cases in English and American history which have allowed for the destruction of property, including ships, docks, and land, when it would have otherwise resulted in the loss of human life. The most significant aspect of this defense in today's legal system can be seen in admiralty law which allows for ships to dump cargo, including oil, in life-threatening situations. Id. at 984-89.

88. Abigail Alliance, $445 \mathrm{~F} .3 \mathrm{~d}$ at 480.

89. Id. (citing RESTATEMENT (FIRST) OF TORTS $\$ 326(1934)$ ).

90. Cruzan v. Dir., Mo. Dep't. of Health, 497 U.S. 261, 277 (1990).

91. Id. at 269 (quoting Union Pac. Ry. Co. v. Botsford, 141 U.S. 250, 251 (1891)). 
explaining that an individual must also be free to decide whether to assume any risks of taking a medication which might prolong his or her life. ${ }^{92}$ If a person is allowed to decline potentially life-saving assistance because of the concept of self-preservation, then a person should also be able to have access to potentially life-saving assistance for the same reason. Furthermore, although there have been a few cases that have rejected a terminally ill patient's right to drugs, those cases involved medication which had not completed Phase I testing, thereby increasing possible risks and, likewise, the government's compelling interest. ${ }^{93}$

It was for such reasons that the Panel found a fundamental right to exist and rendered its decision. It held that "where there are no alternative government-approved treatment options, a terminally ill, mentally competent adult patient's informed access to potentially life-saving investigational new drugs determined by the FDA after Phase I trials to be sufficiently safe for expanded human trials warrants protection under the Due Process Clause."94 The holding seemed to open the doorway for terminally ill patients to finally have access to treatment which had been withheld from them for so long.

\section{Hope Denied?}

The Abigail Alliance decision soon caught the attention of much of the media, as it is seldom that a court of law finds a new fundamental right that has not yet been realized. Also, the element of emotion that exists with regard to terminally ill patients led to even greater publicity. The FDA, however, did not easily relinquish the regulations that it had established and enforced for nearly half a century.

The FDA immediately appealed the decision and, because of the striking implications of the Abigail Alliance holding, the Appeals Court vacated the holding on November 21, 2006. ${ }^{95}$ On August 7, 2007, after rehearing arguments, the full bench of the D.C. Circuit Court rendered an eight to two decision, holding that terminally ill patients have no fundamental right to access drugs which have not been approved by the FDA. ${ }^{96}$ The majority of the Panel, which had previously held that terminally ill patients did have a fundamental right to access drugs pending approval by the FDA, this time joined in a dissenting opinion, arguing that a right to access did exist. ${ }^{97}$

The Circuit Court turned to the Glucksberg test, just as the Panel had, but this time found that the claimed right to access failed to meet the test's requirements. ${ }^{98}$ Assuming arguendo that the asserted right to access satisfied

92. Abigail Alliance, 445 F.3d at 484.

93. Id. at 485-86 (citing Carnohan v. United States, 616 F.2d 1120 (9th Cir. 1980) and Rutherford v. United States, 616 F.2d 455 (10th Cir. 1980)).

94. Id. at 486.

95. Federal Appeals Court to Consider Access Issues. AM. HeALTH LinE, Nov. 27, 2006.

96. Abigail Alliance v. Eschenbach, 495 F.3d 695, 713 (D.C. Cir. 2007).

97. Id. at 714 .

98. Id. at 703-07. 
Glucksberg's "careful description" requirement, the court held that it still failed to satisfy the second requirement of the test, that the right be deeply rooted in this Nation's history, tradition, and practices. ${ }^{99}$ Moreover, it concluded that the issue is not merely whether there is a tradition of access to drugs that have not been proven effective, as argued by Abigail Alliance, but also whether there is a "tradition of access to drugs that have not yet been proven safe."100

In reviewing the history of our Nation's drug regulation, going back as far as the Colonies and early acts passed by state legislatures, the court found that the drug regulation is well-rooted in our Nation's history. ${ }^{101}$ Furthermore, it held that even though there was little drug regulation prior to the 1962 Amendments ${ }^{102}$, "an arguably limited history of efficacy regulation prior to 1962 does not establish a fundamental right of access to unproven drugs." 103 Additionally, the court reasoned that the stream of amendments made to the FDCA throughout the twentieth century exhibited a continuous response by Congress to new risks presented by evolving technology. ${ }^{104}$

The court further explained that a lack of government interference throughout history does not alone prove that an asserted right is deeply rooted. ${ }^{105}$ It reasoned that if such reasoning were allowed, then there could be a swarm of claims for fundamental rights merely because such "rights" were not regulated until recent times. Examples include marijuana use, which was not regulated until 1937, and speed limits, which were obviously unnecessary prior to the twentieth century ${ }^{106}$ Ultimately, the court concluded that " $[T]$ he lack of prior governmental regulation of an activity tells us little about whether the activity merits constitutional protection." 107 Thus, the Alliance's arguments concerning of lack of regulation failed to persuade the court.

Finally, the court examined the common law arguments posed by Abigail Alliance, which the Panel used to justify its finding of a fundamental right firmly rooted in our Nation's history. The court first dealt with Abigail Alliance's argument of necessity, which covers situations "where physical forces beyond the actor's control rendered illegal conduct the lesser of two evils." ed States v. Oakland Cannabis Buyers' Cooperative, the Supreme Court rejected an argument that marijuana for medicinal purposes was a medical necessity. ${ }^{109}$ It held that the defense of necessity "cannot succeed when the leg-

99. Id. at 702-03.

100. Id. at 703 .

101. Id. at 703-05.

102. See supra Part III.B.

103. Abigail Alliance, 495 F.3d at 706.

104. Id.

105. Id.

106. Id. at 707 .

107. Id.

108. Id. at 707 (quoting United States v. Oakland Cannabis Buyers' Coop., 532 U.S. 483, $490(2001))$.

109. Abigail Alliance, 495 F.3d at 708. 
islature itself has made a determination of values."110 Applying that holding to Abigail Alliance, the Circuit Court held that, because Congress has prohibited general access to non-approved drugs, a defense of necessity cannot take precedent over such a determination. ${ }^{111}$

The court then quickly disposed of the arguments of self-defense and intentional interference with lifesaving efforts raised in Abigail Alliance, as both defenses are based on aid that is necessary to the preservation of life. ${ }^{112}$ The experimental drugs for which access is being sought have not been proven safe or effective, and are, therefore, only potentially lifesaving. ${ }^{113}$ Indeed, because of the risks involved, the drugs cannot be considered a necessary aid; thereby, failing to meet the standard for both defenses. ${ }^{114}$

Finding that the asserted right did not meet the minimum requirements for a fundamental right, the Circuit Court next applied the rational basis scrutiny test. ${ }^{115}$ The rational basis test requires that a government restriction or regulation merely bear some rational relationship to a legitimate state interest. ${ }^{116}$ Here, the state interest is protecting patients from the dangers and risks posed by a drug that has not been through the FDA's approval process. ${ }^{117}$ The court explained that "the Government has a rational basis for ensuring that there is a scientifically and medically acceptable level of knowledge about the risks and benefits of such a drug." "In holding that terminally ill patients do not have a right to non-approved drugs, the court advised that the matter was best left to the democratic braches for a determination of the proper balance between the risks and benefits posed by such drugs. ${ }^{119}$

\section{Hope for a Better Tomorrow?}

Abigail Alliance v. Von Eschenbach is expected to reach the United States Supreme Court within the next couple of years. The Supreme Court is in a better position to consider the constitutional implications involved in the possibility of a fundamental right. Also, the case is a sensitive subject between the historical authority of the FDA and the free will of man to make his own decision regarding his chance of survival.

Given that the Supreme Court might consider the issue raised by Abigail Alliance in the near future, it appears timely to consider the ethical dilemmas

110. Id. (quoting Oakland, 532 U.S. at 490).

111. Id.

112. Id. at 708-710.

113. Id.

114. Id.

115. Abigail Alliance, 495 F.3d at 712 .

116. Id.

117. Id.

118. Id. at 713 .

119. Id. See also infra Part IV.B for a discussion about current legislative action regarding patient rights to non-approved drugs. 
and legal factors involved in the issue. Because of the enormous rate of cancer and other terminal diseases in today's world, it is likely that almost every individual has some connection to the topic. Ira Lupa, a professor of constitutional law at George Washington University, acknowledged:

This is the kind of case that you see tugging at people's heartstrings. ... Everyone has a friend or a sibling, or, especially, a child who has a fatal illness. ... You can see that the sympathies attached to this could push a judge who is otherwise quite disciplined over the edge. $^{120}$

Furthermore, if the final decision of the Supreme Court results in a shakeup of the FDA's regulatory scheme, that decision would likely affect, not only the terminally ill, but also the very nature of drug regulation in the United States today.

\section{Should the TERMinAlly ILl Be Allowed to ChoOSE?}

\section{A. Considerations in Favor of Deregulation}

In the past decade, critics of the FDA have been growing rapidly in both number and influence. There are numerous positions that both in favor and oppose the current state of FDA regulation. Aside from the obvious value of human life, economic, legal, and philosophical considerations must be considered in conducting an impartial analysis. This part of the Note evaluates the most prevalent those viewpoints.

The foremost argument for allowing expedited access to new drugs and treatments is that such access might increase the number of cancer survivors. Too often, terminally ill patients have been denied the opportunity to receive a potentially life saving drug until it was too late. One such person was Kianna Karnes. Diagnosed with kidney cancer in 2002, Kianna Karnes, a mother of four in Brownsburg, Indiana, sought treatment from her local doctors. ${ }^{121}$ She began taking interleukin-2, which, at the time, was the only medication approved by the FDA for use against kidney cancer. ${ }^{122}$ The side effects, however, were almost unbearable, so her father, John Rowe, began seeking additional help. In 2004, Rowe learned that the drug manufacturers Pfizer and Bayer had each developed drugs for kidney cancer and were in the process of conducting clinical trials. ${ }^{123}$ After Kianna was denied access to the clinical trials, Rowe

120. Groopman, supra note 3.

121. Id.

122. Id.

123. Id. 
sought help from Dan Burton, a Republican congressman from Indiana. ${ }^{124}$ On March 24, 2005, with Burton's assistance, Rowe finally received permission from the FDA for Kianna to use to the new drugs; Kiana, however, died at 9:41 p.m., that same night. ${ }^{125}$ In January 2006 , both of the experimental drugs developed by Pfizer and Bayer were approved by the FDA as safe and effective treatments against kidney cancer. ${ }^{126}$

Unfortunately, the case of Kianna Karnes is similar to many others. By the time the FDA acted, it was too late to help the terminally ill patient. Had Kianna gained access to the drugs when she first learned of them, they might have saved her, or at least prolonged her life until a better treatment was developed. Kianna's case was unique, however, in that it generated a great deal of noise in Congress. In fact, a law calling for the deregulation of the FDA, currently before the House and Senate, was inspired by and named after Kianna Karnes. ${ }^{127}$

All too often terminally ill patients are forced to sit, wait, and die while a drug passes through all three phases of testing. Indeed, it can take a drug up to twelve years for a drug to complete the required testing and gain FDA approval; ${ }^{128}$ however, a typical terminally-ill patient usually has only a couple of years, at most, to live. Even Dr. Scott Gottlieb, a physician and former senior official for the FDA, has recognized that a problem exists. "Delaying new treatments for the sake of generating more rigorous and complete medical evidence helps patients, to a point. But in the field of cancer . . . the FDA's strict posture is probably overkill." 129 Dr. Gottlieb went on to say that "[t]he FDA is trying to save patients from the harmful effects of new medicines that haven't fully proved their mettle. In the process, many more patients will die waiting for the good medicines than from using the bad ones."130

Another terminally ill patient adversely affected by the FDA's testing scheme wasAbigail Burroughs, whose death lead her father, Frank, to found the Abigail Alliance for Better Access to Developmental Drugs. ${ }^{131}$ Abigail, at only twenty-one years of age, died from cancer in 2001 after being denied access to

124. Id.

125. Groopman, supra note 3.

126. Id.

127. See infra Part IV.A.

128. Walsh \& Pyrich, supra note 20, at 933.

129. Scott Gottlieb, M.D., FDA's Caution Hurting Patients, OKLAHOMAN, May 30, 2005, at $19 \mathrm{~A}$.

130. Id. See also Walsh \& Pyrich, supra note 20 , at 942

In the time taken to conduct a full review of an NDA, thousands of lives might be saved or improved by a new drug or medical device. Moreover, as a result of the long time frame for new drug approval, consumers continue to rely on drugs which, while possibly less safe or less effective, have already been approved.

Id.

131. Robert Manor, FDA Seeks to Ease Access to New Drugs, CHI. TRIB., Dec. 12, 2006, at $\mathrm{Cl}$. 
Erbitux, a drug used to treat cancer of the head, neck, and colon. ${ }^{132}$ Though Erbitux displayed effectiveness during its early clinical phases for treating various forms of cancer, it was not distributed until receiving the FDA's final approval. ${ }^{133}$ As a result, Frank Burroughs decided to fight for those who are in the position his daughter was once in. The Abigail Alliance is given much credit for leading the fight against the FDA and advocating for patient rights.

One argument against deregulation is the increased risk of potential side effects, but most people who are faced with imminent death are less likely to be concerned about a side effect if there is a chance that their life may be prolonged. Furthermore, side effects could hardly be complained of by terminally ill patients who know all too well that the drugs they are taking have not been fully tested. Ultimately, given a choice between prolonging life and the possibility of discomfort or death caused by unknown side effects, a great majority of the population would likely choose the former.

There are alternatives that allow terminally ill patients expedited access to newly manufactured drugs. ${ }^{134}$ For example, clinical trials conducted during the three phases of the FDA's approval process are often opened to those patients with the most serious need. A number of problems are, however, associated with the determination of patient qualification for participation in, and the administration of such clinical trials.

One problem with these clinical trials is the use of placebos. A patient group in a clinical trial is usually divided with a portion of the population getting the actual drug while the remaining patients receive a placebo. ${ }^{135}$ This division allows the doctors to more efficiently monitor the performance and effectiveness of the drug being tested. This testing methodology, however, though scientifically sound, presupposes that at least some terminally ill patients will receive a placebo with no beneficial qualities. How then, should medical professionals determine which terminally ill patients get the placebo? Such a decision, by its very nature, allows a doctor to "play God" by deciding which patients deserve the best shot at survival. Clearly, those patients who receive the placebo would be better off if everyone had access to the drug being tested.

Another issue that arises out of clinical trials is that not all applicants are permitted to participate. For example, a history of brain cancer almost always disqualifies a patient from admittance into a clinical trial. ${ }^{136}$ Brain cancer makes a patient more prone to seizures and can cause symptoms that might in-

132. Id.

133. Id.

134. See infra Part IV.B for an in depth look into alternative paths to various available treatments.

135. Editorial, Last Hope: Terminally Ill People Should Have Access to Experimental Drugs, The Columbus DisPaTch (Ohio), Dec. 20, 2006. See also Pressure for New US FDA Experimental Drug Regulations Could Create Problems, Pharma MARKeTletTer, Dec. 15, 2006.

136. Groopman, supra note 3. 
terfere with the evaluation of the medication. ${ }^{137}$ It was for this very reason that Kianna Karnes was denied access to the clinical trials for the potentially lifesaving drugs designed by Pfizer and; her cancer had spread into her brain. ${ }^{138}$

Also, it may be too expensive or inconvenient for terminally ill patients to get into an applicable clinical trial. Indeed, most clinical trials take several years to complete ${ }^{139}$, and drug companies are likely to conduct such trials at either their own laboratories or in an academic medical center which may be located far from a participant in need. ${ }^{140}$ Furthermore, some American drug companies have been unable to recruit sufficient numbers of interested patients and, as a result, have begun to conduct trials in Europe and Asia. ${ }^{141}$ Gathering the money necessary to make such a move may not be an option for many terminally ill patients. Moreover, if a terminally ill patient has a short life expectancy, he or she might prefer to spend his or her remaining time with loved ones in familiar setting, rather than in an unknown place with invasive clinical monitoring.

Clearly, there are a number of reasons to deregulate the FDA's control over unapproved drugs. Additional reasons also arise specific to each patient's case. However, while the sympathetic and humanitarian part of the population might think that this issue should be quickly dealt with because of the value of the human life at stake, there are many other factors that play into the debate and which must, as a result, be considered.

\section{B. Considerations Against Deregulation}

Most people, including opponents of deregulation, can sympathize with individual patients, such as Kianna Karnes, who have been denied access to potentially life-saving treatments. However, Ralph W. Moss, a medical writer specializing in cancer treatments, noted that, "[w]hile that sentiment is seemingly humane, it is based on a false premise, for it wildly overestimates the effectiveness of most new anti-cancer drugs." "142 Furthermore, the impact of taking away the FDA's authority could bring many unforeseen dangers and potentially create more risks in the long run. ${ }^{143}$

One of the biggest and most obvious concerns associated with allowing non-approved drugs into the market is the inherent uncertainty of their effec-

137. Id.

138. Id.

139. See supra Part II.B.

140. Groopman, supra note 3.

141. Id.

142. Ralph W. Moss, No Way to Save a Life: Allowing Terminally Ill Cancer Patients Access to Drugs That Have Not Completed Clinical Trials is a Dangerous Move, Says Ralph W. Moss, New SCIENTIST, June 3, 2006, at 21.

143. Lois K. Perrin, Note, The Catch-22 for Persons with AIDS: To Have or Not to Have Easy Access to Experimental Therapies and Early Approval for New Drugs, 69 S. CAL. L. REV. 105,145 (1995). 
tiveness. Recall that in Abigail the plaintiffs requested, and the court approved, access to drugs after the completion of Phase I trials. ${ }^{144}$ The problem is that "[ $[$ ] he vast majority of drugs in phase I trials are not lifesaving; they are not even life-prolonging." ${ }^{145}$ Without complete testing, a large number of ineffective, and possibly dangerous, drugs will likely find their way into the market. Many patients "will increasingly fall prey to exaggerated claims for various half-baked drugs, as a result of skillful manipulation of public opinion."146 Desperate patients may hear the untested claims of new drugs and ignorantly consume drugs which could pose greater risks than benefits.

Typically, when new drugs are consumed, it is under the watchful eye of clinical testing. With deregulation, however, side-effects may occur in an uncontrolled atmosphere without any experts nearby to aid the patient. The primary purpose of the FDA is to ensure that public health is not put at risk by dangerous drugs. Indeed, a newly available drug may have "a smaller than expected benefit and a larger than expected adverse effect that could not be recognized without large scale clinical trials of long duration."147 Deregulation could, therefore, serve to erode the monitoring system established by the FDA; thereby, permitting our drug industry to once again exhibit the deficiencies common in the days of Elixir Sulfanilamide and thalidomide. ${ }^{148}$

Phase I testing, opponents of deregulation argue, is not an effective enough screening process to serve as a catch-all before releasing drugs. ${ }^{149}$ One such opponent explained:

There are very small numbers of participants in Phase I, and they are treated for a very limited period of time. So if you believe that there is this constitutional right, that there are risks you are willing to take and not have the government interfere, why have a cutoff at Phase I? Why not just say, 'Any drug I'm willing to take,' because of some anecdotal experience, or some animal study, or the molecular structure, is reason to think the drug might work? $?^{150}$

Also, Phase I does not test as much for effectiveness as it does safety. ${ }^{151}$ Therefore, even if a terminally ill patient gets his hands on a post-Phase I drug that

144. Abigail Alliance v. Eschenbach, 445 F.3d 470, 473 (D.C. Cir. 2006).

145. Moss, supra note 142.

146. Id.

147. Perrin, supra note 143, at 144.

148. Abigail Alliance, 445 F.3d at 482.

149. Groopman, supra note 3.

150. Groopman, supra note 3, (quoting Sonia Suter, a professor of law at George Washington University and an expert in medical ethics).

151. See supra Part II.B. 
won't harm him, he could be spending unnecessary money, hope, and time with a drug that produces no results.

Another serious concern with deregulation is the impact that it would have on clinical trials. These trials are the most important part of the approval process. ${ }^{152}$ They provide the data and results which are used to determine whether a drug meets the market standards for safety and efficacy. If, however, drug manufacturers are allowed to bypass the clinical trial process, many patients will lose their incentive to participate in such trials. ${ }^{153}$ If patients are able to obtain experimental drugs on their own, they suddenly have little reason to incur the cost and inconvenience of leaving home to participate in trials. ${ }^{154}$ While on its face this may appear to be a benefit to terminally ill patients, the longterm results could prove devastating to the medical industry.

Drug companies already have a difficult time recruiting patients to participate in clinical trials. ${ }^{155}$ With deregulation, clinical trials, on a local level, might become cost ineffective. This could mean the end of scientific and medical studies in human clinical testing. As professor Norman C. Frost explained,

There's a strong societal interest in advancing knowledge and having new drugs done in trials first rather than in the marketplace, because otherwise we don't learn anything and we waste not only lots of money but sometimes lives, and there's no advancement so we remain in a state of perpetual ignorance. ${ }^{156}$

Clinical trials provide drug companies and the medical industry with much cutting edge knowledge directly related to the treatment of terminal illnesses. If the ability to effectively conduct such trials is lost, then the ability to treat terminal illnesses could be adversely effected. Moreover, the loss of clinical trial efficacy could undercut the preferences of those patients who desire to take drugs only after they have passed clinical testing. Therefore, "the benefit of a few desperate [and outspoken patients] would come at a steep cost for the rest of us. . .."157 Instead, opponents argue that there needs to be a balancing of interests between those who want immediate access to untested drugs and those who prefer to wait for the FDA's stamp of approval. ${ }^{158}$

Another possible effect of deregulation is that drug manufacturers could lose their incentive to conduct thorough research. If drug manufacturers know that they do not have to meet the same standards of the FDA's current approval

152. Casanova, supra note 12 .

153. Groopman, supra note 3.

154. Id.

155. See supra Part IV.A.

156. Casanova, supra note 12 (Dr. Fost is professor of pediatrics and the chair of the ethics committee at the University of Wisconsin Hospital).

157. Ezekiel J. Emanuel, Drug Addiction, NEW REPUBLIC, July 3, 2006, at 9.

158. Casanova, supra note 12. 
process, what motivation will they have to go above and beyond to ensure a drug's safety and effectiveness? Not only is medical and pharmaceutical research costly, but it also takes time to conduct preliminary testing. Deregulation would almost necessitate that drug manufacturers pursue a guess-andcheck strategy. As such, drug manufacturers would be tempted to get a drug into the market quickly, without regard for potential liability, in order to test the drug's effectiveness and gain a quick return on their investment. This raises another problem: who does liability fall upon if there is no regulation?

Pending legislation concerning this matter, discussed supra, stipulates that drug manufactures cannot be held responsible for a patient's adverse reactions to experimental drugs. ${ }^{159}$ So if a drug manufacturer cannot be held liable for its own dangerous drug, then who assumes liability? The result could be an unprecedented degree of assumption of risk. Also, if there is no liability for such drugs, ignorant retailers with little or no scientific experience might be encouraged to take their shot at drug manufacturing. This scenario "opens the space for products that are sold by charlatans." 160 The dangers that are posed by such a situation are blatantly obvious.

In the alternative, if drug manufacturers are held liable in a world of deregulation, they may lose incentive to make experimental drugs widely available. $^{161}$ Currently, drugs are not approved for Medicare or for insurance purposes until after they have completed the FDA's approval process. ${ }^{162}$ If drug manufacturers are unable to obtain appropriate insurance or find distributors because they distribute drugs that have not yet satisfied the FDA's approval process, they may choose to completely forego the liability of such exposure and proceed with the FDA's approval process before releasing the drugs into the market; thereby, completely bypassing terminally ill patients in immediate need.

\section{Legal Concerns Regarding Deregulation Versus the Right of Terminally Ill Patients to Choose Non-FDA Approved Drugs}

Apart from institutional factors surrounding the debate over deregulation, the outcome will also likely raise legal concerns in the health law industry. In his dissenting opinion in the en banc panel's decision of Abigail Alliance, Justice Thomas Griffith, who wrote the majority opinion for the full bench, raised several legal issues posed by the issue of terminally ill patients and experimental drugs. While these issues were not discussed in the latter decision, they are of importance in analyzing the matter of deregulation.

159. Groopman, supra note 3.

160. Groopman, supra note 3 (quoting David Parkinson, an oncologist who worked at the National Cancer Institute and who now serves as senior vice-president of a large biotech company).

161. Id.

162. Id. 
Justice Griffith's first question related to the definition of "terminally ill patients" and the breadth of its application. "[A]re patients with serious medical conditions entitled to the benefit of the same logic and corresponding access?"163 Why should a patient suffering unbearable pain, or plagued with a lifelong illness, be denied a potentially pain-relieving drug simply because she is not guaranteed that she will die as a result of her illness? It is difficult to argue that such a patient's suffering is less worthy than that of a person facing imminent death.

Another question posed by Justice Griffith was whether a patient can access any drug if, after consulting a physician, she believes that it will ease her suffering or possibly save her life. ${ }^{164}$ One can easily picture individuals devising ways to take advantage of such an opportunity, claiming that, narcotics will save them from a lifetime of pain. Indeed, under such a theory, the movement to legalize medicinal marijuana might also regain momentum, as advocates look for loopholes in deregulation. ${ }^{165}$ How would the system distinguish between non-approved medicinal drugs from those generally thought of as narcotics?

Along that same line, a question that Justice Griffith thought most significant was "what potential must a treatment have in order for the Constitution to mandate access?"166 If a patient does have a fundamental right to a potentially life-saving medication, the government probably has little role to play in deciding its actual effectiveness. The Abigail Alliance, however, has requested access to drugs only after they have passed through Phase I. The FDA, therefore, would still have a large role in deciding what drugs pass through the first phase of trials. But should those standards be relaxed or tightened?

Still another concern is that untested drugs could fall into the wrong hands. A scenario can be imagined in which a terminally ill patient is given free access to new drugs. How will the government ensure that such drugs stay with the terminally ill patient? There is a definite concern that a surplus of untested drugs could enter the market and become available to those without a fundamental interest in them.

The debate over deregulation has given rise to many questions and legal concerns. Congress and the FDA have begun to address some of these concerns. Despite the fact that the Panel's decision was vacated, however, its holding generated such a buzz within the medical industry that it prompted what may be considered a preemptive strike by the FDA.

163. Abigail Alliance, 445 F.3d at 499 (Griffith, J., dissenting).

164. Id.

165. See Gonzales v. Raich, 545 U.S. 1,1 (2005) (affirming Congress' power to regulate intrastate marijuana consumption, even for medicinal purposes).

166. Abigail Alliance, 445 F.3d at 499 (Griffith, J., dissenting). 


\section{THE FUTURE OF THE FDA'S APPROVAL PROCESS REGARDING TERMINALLY ILL PATIENTS' ACCESS TO UNAPPROVED DRUGS}

\section{A. A Preemptive Strike?}

On December 11, 2006, less than three weeks after its appeal was granted and the District of Columbia Circuit Court announced that it would rehear the Abigail case, the FDA announced that it planned to make changes intended to help terminally ill patients more easily access new drugs. ${ }^{167}$ In part, the changes entailed broadening the guidelines for when such drugs may be used and making those guidelines more explicit within the medical industry. ${ }^{168}$ The FDA hopes this "will give physicians clear directives on when to grant access to medications, even perhaps at the very earliest stage of development, in cases in which the potential benefit is deemed to outweigh the risks." 169 Because doctors are not regulated by the FDA, they often prescribe drugs for different off-label uses, not realizing that the drug has not been approved for such use. ${ }^{170}$ Increasing the awareness among physicians will hopefully deter them from providing patients with false hope in some ineffective drugs.

Furthermore, the FDA realizes that many viable treatment options have been overlooked. ${ }^{171}$ One spokesman for the FDA announced, "[w]e expect that clearly articulating procedures and standards for expanded access will result in more patients with serious or immediately life-threatening diseases or conditions getting the earliest possible access to these therapies."172 The FDA, however, has not been very specific or detailed in explaining exactly how it plans to allow access to new drugs for terminally ill patients.

It is possible that the announcement was a preemptive strike, made in response to the future rehearing of the $\mathrm{Abigail}$ case. If the FDA can portray itself as an adaptable agency capable of taking responsibility for making changes, then the Court may be less likely to impose its own strict standards on the agency. Only with the passage of time will we be able to determine the sincerity of the FDA's new plan of reform and the effectiveness of its proclaimed changes.

\section{B. Legislative Action}

Senator Sam Brownback of Kansas and Representative Christopher Shays of Connecticut have introduced bills in the Senate ${ }^{173}$ and House of Representa-

167. Manor, supra note 131.

168. Id.

169. Id.

170. Abigail Alliance, 445 F.3d at 483.

171. Manor, supra note 131.

172. Id.

173. Access, Compassion, Care, and Ethics for Seriously-ill Patients Act, S. 1956, 109th Cong. (2005). 
tives ${ }^{174}$, respectively, to amend the Federal Food, Drug, and Cosmetic Act. The legislation would create a new three-tiered approval system for drugs, biological products, and medical devices that is responsive to the needs of seriously ill patients. ${ }^{175}$ The Access, Compassion, Care, and Ethics for Seriously-ill Patients Act, better known as the ACCESS Act, was introduced in the Senate on November 3, 2005, and was referred to the Committee on Health, Education, Labor, and Pensions the same day. ${ }^{176}$ The bill was introduced in the House on September 29, 2006, and was referred to the Subcommittee on Health on October 2, 2006. ${ }^{177}$ Although this legislation is still pending, if passed, it could seriously shake up the FDA and its current approval process.

In effect, the ACCESS Act appears to effectively upend the FDA's current regulatory structure. Some of the bill's pertinent findings include:

(1) The necessity of placebo controlled studies has been questioned on both scientific and ethical grounds for seriously ill patients.

(3) Promising therapies intended to treat serious or life threatening conditions or diseases and which address unmet medical needs have received unjustified delays and denials of approvals.

(5) The current Food and Drug Administration and National Cancer Institute case-by-case exception for compassionate access must be required to permit all seriously ill patients access to available experimental therapies as a treatment option.

(8) The use of available investigational products for treatment is the responsibility of the physician and the patient. $^{178}$

The legislation's sponsors clearly do not favor the FDA's methods or reasoning. Indeed, the ACCESS Act proposes an entirely new expedited approval process and grants much more rights to the terminally ill.

The ACCESS Act would provide greater access to new drugs in several ways. First, the bill proposes an expedited three-tiered system, with established timeframes, that a drugs' sponsor must meet. With regard to the first of the

174. Access, Compassion, Care, and Ethics for Seriously-ill Patients Act, H.R. 6303, 109th Cong. (2006).

175. H.R. 6303.

176. S. 1956.

177. H.R. 6303.

178. S. $1956 \S 2$. 
three tiers, a key difference in the approval process is that it is based primarily upon clinical evaluation rather statistical analysis. ${ }^{179}$ In order for a new drug, treatment, or device to gain Tier I approval, a sponsor must submit an application containing:

(i) data and information from completed Phase I clinical investigations and any other nonclinical or clinical investigations;

(ii) preliminary evidence that the product may be effective against a serious or life-threatening condition or disease, which evidence may be based on uncontrolled data such as case histories, information about the pharmacological mechanism of action, data from animal and computer models, comparison with historical data, or other preliminary information, and may be based on a small number of patients; and

(iii) an assurance that the sponsor will continue clinical investigation to obtain Tier III approval. ${ }^{180}$

It is evident that it would be easier and much less time consuming for a drug to gain Tier I approval than it is for the same drug to gain Phase I approval under the FDA's current structure. ${ }^{181}$ A drug sponsor would have to show only that the drug or treatment could possibly be effective for its intended use. Furthermore, it appears that a drug sponsor would be able to make this showing much sooner under the proposed system because the Act would allow greater reliance on animal and computer testing, rather than waiting for patients to sign up and complete a number of clinical trials. The Act also contains the safeguard that a drug sponsor must continue to pursue research and testing in order to complete all three Tiers. This would deter drug manufacturers from simply relying on an incomplete (or preliminary) study without further follow up. Instead, those manufacturers must be both accountable and efficient to fully promote their new drugs. Also, the Act requires the Secretary, no later than thirty days after the receipt of an application, to either approve the application or refer it to a special committee. ${ }^{182}$

Another way in which the ACCESS Act would expedite the process and provide greater access to drugs is that it requires the FDA to establish an Accelerated Approval Advisory Committee. ${ }^{183}$ This committee, comprised of eleven

179. S. $1956 \S 3$.

180. Id. (proposing to amend $\S 506(\mathrm{~b})(1)$ of the Federal Food, Drug, and Cosmetic Act (21 U.S.C. 356)) (emphasis added).

181. See supra Part II.B (discussing the length of time and the requirements that a drug must meet before receiving approval for Phase I testing).

182. S. $1956 \S 3$ (proposing to amend $\S 506(\mathrm{~b})(2)$ of the Federal Food, Drug, and Cosmetic Act (21 U.S.C. § 356)).

183. S. $1956 \S 3$ (proposing to amend $\S 506$ of the Federal Food, Drug, and Cosmetic Act 
members, ${ }^{184}$ will, upon a referral by the Secretary, have ninety days to review an investigational new drug. ${ }^{185}$ Within thirty days of receiving the Accelerated Approval Advisory Committee's recommendation, the Secretary must decide whether or not to approve the drug for the requested Tier. ${ }^{186}$

The criteria to be considered in deciding whether or not to approve an application are based upon a balanced consideration of the risks posed by the disease and the potential risks of the proposed drug. "If the potential risk to a patient of the condition or disease outweighs the potential risk of the product, and the product may possibly provide benefit to the patient, the Secretary shall approve the application." ${ }^{187}$ Once a drug has achieved Tier I approval, it is to be made available only to a patient whose physician has documented in writing that the patient has exhausted all other available options and that none were effective. $^{188}$

Also, the patient must give informed written consent, sign a waiver of the right to sue the drug's sponsor and manufacturer and the physician who recommended the drug, and consent to release to the drug manufacturer information about the patient and his or her use of the drug. ${ }^{189}$ This provision addresses many of the concerns presented by critics of deregulation. It insures that liability will not rest with any party involved in the transaction. Instead, a patient assumes all risk in undertaking the treatment. Furthermore, the provision insures continuing research and testing of the drugs by requiring patients to submit data and information relating to their treatment.

Additionally, while the standards for Tier II approval are similar to those of Tier I, it requires more than a mere possibility of effectiveness. A drug's sponsor must demonstrate that its product "has an effect on a clinical endpoint . .. that is reasonably likely to predict clinical benefit to a patient . . . suffering from a serious or life-threatening condition or disease."

Finally, Tier III approval meets the same standards as that which is already defined by the FDA.

One last interesting proposed element of the ACCESS Act is that it allows the Secretary to withdraw Tier I and Tier II approval in four situations. Specifically, approval can be withdrawn if: (1) the sponsor fails to conduct continuing studies with due diligence; (2) a post-approval study fails to verify the

(21 U.S.C. § 356) to add a new subsection (g)).

184. S. $1956 \S 3$.

185. Id. (proposing to amend $\S 506(\mathrm{~b})(2)(\mathrm{B})$ of the Federal Food, Drug, and Cosmetic Act (21 U.S.C. § 356)).

186. S. $1956 \S 3$ (proposing to amend $\S 506(\mathrm{~b})(2)(\mathrm{C})$ of the Federal Food, Drug, and Cosmetic Act (21 U.S.C. § 356)).

187. S. $1956 \S 3$ (proposing to amend $\S 506(\mathrm{~b})$ of the Federal Food, Drug, and Cosmetic Act (21 U.S.C. $\$ 356$ ) by adding a new paragraph (b)(4)).

188. S. $1956 \S 3$ (proposing to amend $\S 506$ (b) of the Federal Food, Drug, and Cosmetic Act (21 U.S.C. $\S 356$ ) by adding a new subparagraph (b)(5)(A)).

189. Id. (proposing to amend $\S 506$ (b) of the Federal Food, Drug, and Cosmetic Act (21 U.S.C. $\S 356$ ) by adding a new subparagraph (b)(5)(B)).

190. S. $1956 \S 3$ (proposing to amend $\S 506$ of the Federal Food, Drug, and Cosmetic Act (21 U.S.C. § 356) by adding a new subsection (f)). 
product's benefit for even a small patient subpopulation; (3) evidence is introduced demonstrating that the product is not safe or effective for even a small patient subpopulation; or (4) the drug's sponsor disseminates false or misleading promotional materials and fails to promptly correct the material after receiving written notice. ${ }^{191}$ This provision acts as another check on manufacturers to ensure that they remain accountable to the FDA.

The ACCESS Act would clearly upend the FDA's current approval system and provide better access to the terminally ill. The legislation, however, still leaves room for debate over the subpopulation to which expedited access is available and the use of narcotics such as medicinal marijuana. Furthermore, the ACCESS Act has been pending before Congress for over a year with no results. It is still unclear whether Senator Brownback and Representative Shays will prevail before their colleagues. Given the debate's history and rising intensity, it seems rather clear that this will not be the last bill of its kind proposed in Congress.

\section{Drug Regulation Around the World}

As noted above, the FDA's current regulatory structure, for drugs, is considered to be the most stringent in the world. ${ }^{192}$ Compared to other countries, it is much more difficult to get access to drugs in the United States because of the stricter standards and longer testing phases required here. The result is that many American patients will often flee to other countries where potentially lifesaving drugs are made more available. It is sad to think that a regulatory structure designed to protect the people of the United States drives consumers to other, sometimes poverty-stricken nations, to get one last shot at survival. Given this reality, it is necessary to ask: (1) how other countries regulate their drugs, and (2) whether those regulatory schemes have been successful.

\section{Great Britain}

Although the British drug approval system resembles the American approach more closely than any other nation's system, it is generally recognized as more objective and expeditious than the FDA's structure. ${ }^{193}$ The primary mechanism for prescription drug regulation in Great Britain is the Medicines Act of 1968. ${ }^{194}$ Under the Act, the Medicines Division of the Department of Health and Social Services first issues certificates that allow drugs to be admin-

191. S. $1956 \S 3$ (proposing to amend $\S 506(c)(1)(A)$ of the Federal Food, Drug, and Cosmetic Act (21 U.S.C. § 356)).

192. See generally Dillman, supra note 4.

193. Dillman, supra note 4, at 931 (citing Note, International Trends in New Drug Approval Regulation: The Impact on Pharmaceutical Innovation, 10 RUTGERS COMPUTER \& TECH. L.J. 317, 317 (1984).

194. Id. at 932 . 
istered to human beings and then issues licenses allowing the drugs to be marketed to the public. ${ }^{195}$

One significant difference between the American and British systems is that, in Britain, certification is not required for physicians who want to administer drugs to their own patients for therapeutic use. ${ }^{196}$ Thus, the British system provides more flexibility to resident doctors than does the FDA. Furthermore, drugs are usually made sooner and more widely available to the British market.

Before the passage of Britain's Medicines Act, the United States led Great Britain in drug development. ${ }^{197}$ Since that time, however, Great Britain has turned the tide, shepherding drugs through the development process, on average, five years faster than in the United States. ${ }^{198}$ Furthermore, according to a test conducted after the passage of the Medicines Act, "Great Britain had nearly four times as many exclusively available drugs in the same time period as did the United States." 199 In spite of Britain's faster and greater distribution of drugs to its consumers, there have not been any findings of excessive new drug toxicity as a result. ${ }^{200}$

\section{Germany}

Germany is the global leader in the availability of pharmaceutical drugs. ${ }^{201}$ It has some 8900 available drug products compared to the 6000 available in the United States. ${ }^{202}$ Although some of the disparity can be attributed to the fact that many large drug manufacturers, such as Pfizer, reside in Germany, Germany's less burdensome regulation also contributes to the large number of available drug products there.

While the regulation of drugs in the United States is the responsibility of government officials, that responsibility in Germany mainly lies with members of the medical profession, which has "retained greater autonomy to design and oversee clinical testing." 203 Another difference between the two nations is that "patients in the United States increasingly challenge expert risk assessments and demand access to drugs, even in early stages of clinical trials. A comparable politics of patient identity and access to medicines is strikingly absent in Germany, where professional associations continue to operate as intermediaries

195. Id. The clinical trial certificates and marketing licenses last for two and five years, respectively, after which time renewal is required. Id.

196. Id. at 933.

197. Walsh \& Pyrich, supra note 20 , at $939-40$.

198. Id. at 940 .

199. Dillman, supra note 4, at 934.

200. Id. at 934-35.

201. Arthur A. Daemmrich, Pharmacopolitics: Drug Regulation IN the United States AND GeRmanY 9 (The Univ. of N.C. Press 2004).

202. Id.

203. Id. at 6 . 
between citizens and the state." ${ }^{204}$ Whether or not this is a result of German culture or politics, it is clear that the delegation of drug monitoring to the medical profession has improved the access to drugs in Germany. Furthermore, the fact that many of the world's largest drug manufacturers reside in Germany is evidence that the system there is working.

\section{World Health Organization}

The World Health Organization ("WHO") ${ }^{205}$ works to fulfill its goal in essential drug and medicine policy by providing global guidance on essential medicines. Specifically, WHO works with countries around the world to implement national drug policies that ensure equitable access to essential medicines, the quality and safety of medicines, and, by implication, the rational and systematic use of medicines. ${ }^{206}$ In many of the countries within WHO is working, including Kenya, Myanmar, and Vietnam, only fifty percent of drugs on the market are registered. ${ }^{207}$ Because of the lack of regulation in these countries, there are large amounts of counterfeit drugs in the market. ${ }^{208}$ Furthermore, failed drugs from other countries are often smuggled into these markets; thereby, creating even greater risks. ${ }^{209}$ For these reasons, Americans should be careful when traveling to other countries, especially third-world countries and countries without systematic drug regulation systems, to receive broader access to alternative treatments. For some terminally ill patients, however, traveling to another country for treatment is their one last shot to receive a drug that has been denied to them by their own government.

\section{Privatization as an Alternative}

One proposed solution to the delays and costs engendered by the FDA's approval process is privatization, "namely, delegation of some of the FDA regulatory functions to private entities under FDA supervision."210 Privatization has been a solution to numerous governmental regulatory problems in the past, including railroads, development, and building contracts. ${ }^{211}$ Delegation of

204. Id.

205. The World Health Organization ("WHO") is the United Nations specialized agency for health. It was established on April 7, 1948 with the objective of helping all people to attain the highest possible level of health. Health is defined, in WHO's Constitution, as "a state of complete physical, mental, and well-being and not merely the absence of disease or infirmity." WHO CONST. pmbl., available at http://www.who.int/governance/eb/ who_constitution_en.pdf.

206. See Wondemagegnehu, supra note 15.

207. Id at 34-35.

208. See Id.

209. See Id.

210. Walsh \& Pyrich, supra note 20, at 954.

211. Id. 
the FDA's regulatory duties would allow it to take advantage of a number of benefits that are typically not available to government agencies.

The first advantage of delegation is that it would allow the government to use the expertise and resources available in the private sector. ${ }^{212}$ Private entities are usually able to pay higher salaries and offer more benefits; thereby, attracting better, talented, and more experienced individuals who are not always available in the market for public employment. ${ }^{213}$ Furthermore, delegation preserves scarce government resources as private parties can often operate and function more efficiently than the government. ${ }^{214}$

Another advantage of privatization is that private entities are not subject to politics." "Since private parties are not dependent on ... public . . . funding, they may more freely address politically sensitive issues." ${ }^{216}$ Also, the private sector does not have to deal with the bureaucratic processes and procedural restrictions often imposed on government agencies; thereby, enabling them to respond more efficiently in many circumstances. ${ }^{217}$

Privatization, however, is an unlikely alternative. The FDA "has been reluctant to yield its authority over drugs and medical devices for fear that public health and safety will be compromised." ${ }^{218}$ Furthermore, private entities may be reluctant to assume the liability that comes with the territory. Nevertheless, privatization remains a possible solution to the problem.

\section{CONCLUSION}

The issues surrounding access of the terminally ill, to drugs and treatments unapproved by the FDA, involves emotionally charged stories such as those of Kianna Karnes and Abigail Burroughs. These stories complicate and humanize the issues involved, because it is human nature, not only to mourn the loss of a valuable life, but also to fight for survival. Given the compelling nature of these tales, it is easy to respond to the emotional pull of this issue by summarily concluding that deregulation is the obvious answer: Indeed, on a fundamental level, it seems logical to assert that government should not be permitted to interfere with an individual's right to survival. Moreover, if a terminally ill patient wants to assume the risks associated with the use of an unapproved, but potentially lifesaving drug, then the urge is strong to permit him or her to take that risk, especially when the patient faces imminent death anyway. The thought of government forcing a dying person to wait, while dangling the

212. Id.

213. Id. at 955 .

214. Id.

215. Id. at 956.

216. Walsh \& Pyrich, supra note 20, at 956.

217. Id.

218. Id. at 1040. 
hope of life over her head, while a decade of clinical testing is completed, can seem seriously offensive and cruel.

This issue, however, is more complex than that simplistic approach, and emotions can distort otherwise rational and unbiased minds. While some may not even want to consider arguments against letting a dying individual to receive potentially life-saving treatment, those arguments are do exist and possess strength of reason. There is, and should be, great empathy for those who have lost someone close or who currently suffer from a terminal illness, but the answer to this problem is more complicated than simply opening the gateway to pharmaceutical drugs for every person faced with death. In reality, the negative consequences of deregulation are quite evenly balanced with its benefits.

These considerations notwithstanding, however, the FDA's approval process definitely needs modification. Ten years is too long for the publicand especially the terminally ill - to wait for drugs to be tested, approved, and made available. The United States should look to Great Britain for guidance, because it has managed to maintain a reasonable level of safety but has still been able to get drugs into the market more quickly than the United States. Also, Senator Brownback's ACCESS Act proposes many suggestions that could revolutionize the FDA's approval process. Just how long it would take, however, to fully implement a new system is presently unknown.

Even so, terminally ill patients should not be forced to wait for a drug to pass through three phases of testing. Expedited access to new treatments after Phase II, if not Phase I, is more appropriate, given the short life expectancy for this group of individuals. Also, expanded access to clinical trials conducted by both government and private entities should be made available to such patients. Indeed, even if patients with a terminal illness do not possess a fundamental right to obtain potentially life-saving drugs, the basic right of self-survival should at least provide them access to clinical trials.

Assuming that the Abigail Alliance case reaches the Supreme Court ${ }^{219}$, it is difficult to gauge how the Court will determine the issue. Regardless of whether the Court recognizes a fundamental right in terminally ill patients to the use of experimental drugs, there will likely be modifications to, if not an overhaul of, the current system because it is currently producing unsatisfactory results. Whatever the Court decides, it seems certain that this debate will not, as have so many terminally ill patients, go quietly into the night. 
